\title{
A DIGITAL IMAGING TEGHNIQUE TO QUANTIFY THE INGIDENGE OF INTERNAL BROWNING IN POTATO (SOLANUM TUBEROSUM) TUBERS
}

\author{
By S. M. HARPER $\dagger$ and F. P. C. BLAMEY $\ddagger$ \\ Horticulture and Forestry Science, Queensland Department of Primary Industries and Fisheries, \\ Gatton, Queensland 4343, Australia and $\ddagger$ School of Land, Crop and Food Sciences, \\ The University of Queensland, Brisbane, Queensland 4072, Australia
}

(Accepted 3 July 2007)

\begin{abstract}
SUMMARY
Internal browning disorders, including brown fleck $(\mathrm{BF})$, in potato (Solanum tuberosum) tubers greatly reduce tuber quality, but the causes are not well understood. This is due, in part, to the highly variable data provided by visual value-based rating systems. A digital imaging technique was developed to quantify accurately the incidence of internal browning in potato tubers. Images of tuber sections were scanned using a flatbed scanner and digitally enhanced to highlight tuber BF lesions, and the area of affected tissue calculated using pixel quantification software. Digital imaging allowed for the determination of previously unused indices of the incidence and severity of internal browning in potato tubers. Statistical analysis of the comparison between digitally derived and visual-rating BF data from a glasshouse experiment showed that digital data greatly improved the delineation of treatment effects. The $F$-test probability was further improved through square root or logarithmic data transformations of the digital data, but not of the visualrating data. Data from a field experiment showed that the area of tuber affected by BF and the number of small BF lesions increased with time and with increase in tuber size. The results from this study indicate that digital imaging of internal browning disorders of potato tubers holds much promise in determining their causes that heretofore have proved elusive.
\end{abstract}

\section{INTRODUGTION}

Many disorders affect the internal quality of the potato (Solanum tuberosum) tuber, all of which economically impact on potato production worldwide (Stevenson et al., 2001). The causal mechanisms broadly relate to influences of pathogenic or environmental origin. The latter, generally referred to as physiological disorders, occur in the absence of pathogen infection, producing no external symptoms on the tuber or the plant foliage.

The range of these physiological internal disorders includes brown fleck $(\mathrm{BF})$, internal brown spot, internal heat necrosis and physiological necrosis (Stevenson et al., 2001; Strand et al., 1986). However, the disorders have not been well defined nor their causal mechanisms well understood (Hiller et al., 1985). The incidence of these disorders has been related to fluctuating growing conditions due to factors such as changes in temperature, improper cultural practices, inadequate and excessive 
soil fertility or soil moisture levels, and other factors that alter normal growth and development of the potato plant, including the tuber (Hiller et al., 1985).

Difficulty in understanding the causal mechanisms can be attributed, in part, to the highly variable field incidence and the variability of the subjective techniques used to quantify incidence. Traditional methods for quantifying the incidence of internal disorders of tubers have relied on a subjective estimation based on visual assessment. These approaches have included recording the presence or absence of symptoms, the number of tubers affected and systems based on visual ratings (Collier et al., 1980; Novak et al., 1986; Sterrett and Henninger, 1991). Sterrett and Henninger (1991) adopted a colour plate rating system with a range of 1-9 (i.e. no symptoms present - high incidence) to rate the severity of internal heat necrosis. Combinations of scaled ratings and percentages of tubers affected have also been used as an index of severity of internal brown spot (Olsen et al., 1996). All these subjective assessments have presented difficulties, particularly with experiments conducted over many seasons (Ahmadi et al., 1960).

The advent of computer scanners, photographic enhancement and pixel quantification software has provided an opportunity to quantify accurately the incidence of internal disorders in potato tubers. For example, digital imaging has been used to quantify the incidence of pathogen-induced lesions and to screen potato germplasm for resistance to late blight (Phytophthora infestans) (Kowalski and Cassells, 1999; Niemera et al., 1999).

The potential to quantify accurately the incidence and severity of internal tuber disorders using computerized digital imaging offers an opportunity of providing sound statistical analysis of experimental results and, consequently, more meaningful interpretations of treatment effects. This paper describes a computerized digital imaging technique developed to quantify the incidence of BF including lesion area and number.

\section{MATERIALS AND METHODS}

The method developed in this study involved (i) cutting cross-sections of potato tuber, (ii) scanning these sections using a flatbed scanner, (iii) image enhancement, and (iv) determination of BF-affected area using image measuring computer software.

Cross-sections of tubers (approx. $8 \mathrm{~mm}$ thick) were progressively cut to expose BF lesions. The section with the most intense lesion development was selected to determine the area affected with BF and the number of BF lesions. Cutting tubers, particularly those with BF, often causes browning of the cut surface through the reaction of polyphenol oxidase (Brown et al., 1999). This causes problems in the measurement of BF through overestimation of the affected area. To overcome this problem, cut sections were immediately washed with distilled water. When a delay of more than several minutes was expected between cutting the tuber and scanning, samples were stored for several hours at room temperature in an aqueous solution of $2 \%$ citric acid and 1\% ascorbic acid, thereby preventing the browning reactions. 


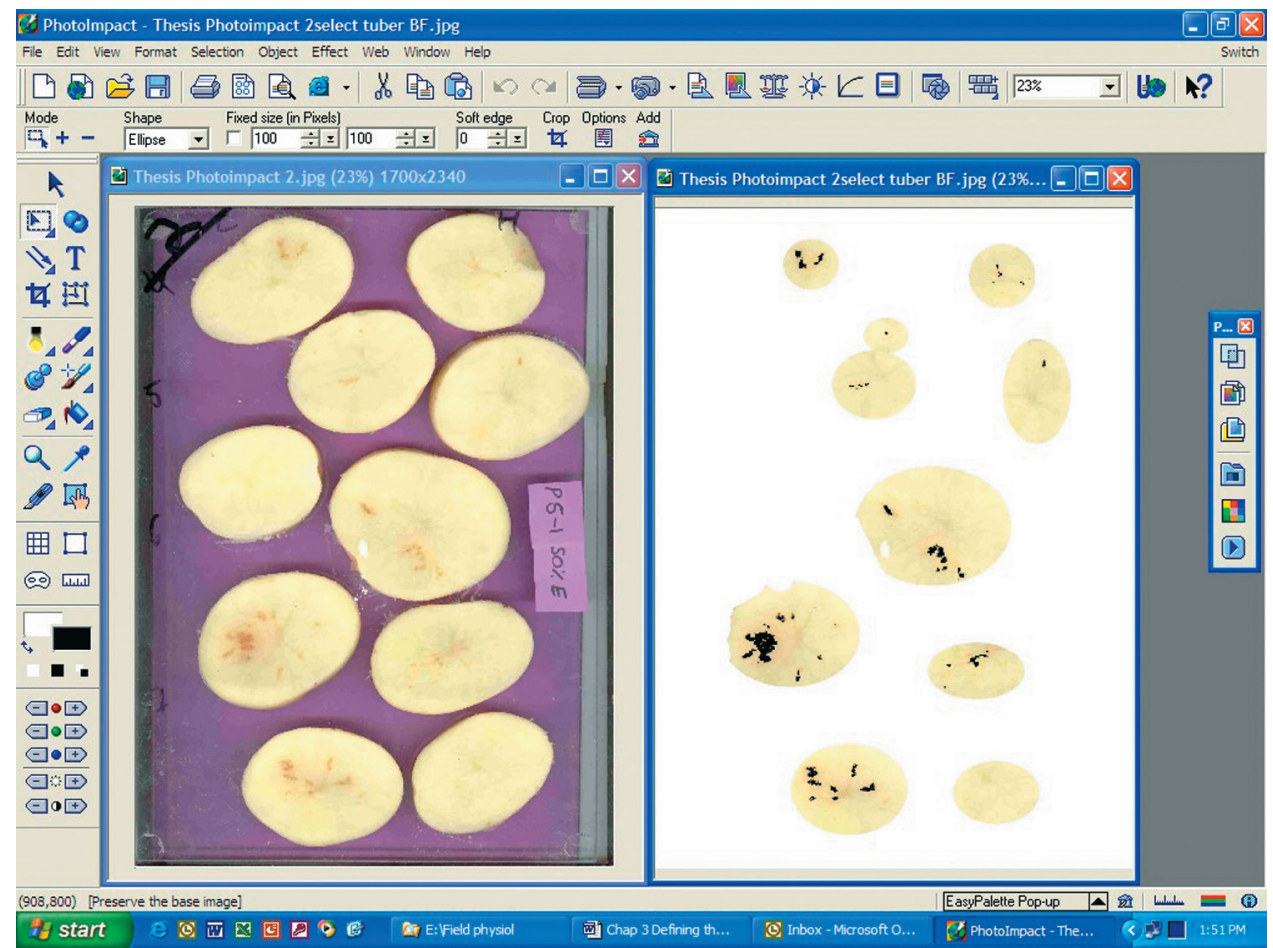

Figure 1. The PhotoImpact(C 7.0 for Microsoft Windows ${ }^{\circledR}$ display showing the initial scanned digital image of potato cv. Sebago tuber sections (left) and the selected tissue sections with BF enhancement in black (right).

Tuber sections were placed between two A4-sized sheets of $3 \mathrm{~mm}$-thick clear glass to prevent tuber exudate contaminating the scanner surface and cover. The glass sheets and tuber sections were placed on a Hewlett Packard Scanjet 5470c scanner bed and a coloured cover sheet placed over the top to provide a contrasting background. The images were scanned as JPEG files in True Color (16.7 million colours) using HP Precision Scan 3.1 software. The scanned image was then imported into an image enhancement package $\left(\right.$ Ulead $^{\circledR}$ PhotoImpact $\left.{ }^{\circledR} 7.0\right)$ to highlight the pixels associated with BF. A comparison of the initial and enhanced images is presented in Figure 1.

Portions of tuber sections affected with BF were selected using the various shape selection modes, the image background changed to white using the 'paintfill' feature and the selected objects merged. The lesions associated with BF were then changed to black by using the 'colour replacement pen' feature. If necessary, the colour to be replaced may be varied from year to year depending on the extent of BF incidence and its intensity. In the present study, this was in the order of a chroma setting of 180 250 Red, 140-190 Green and 70-140 Blue. The similarity feature was progressively increased to ensure that the full lesion colour was changed. During the scanning process, the light exposure varied depending on the number of sections scanned, and this subtly influenced the brightness and colour of the scanned image. Therefore, the enhanced images were checked against the original image to ensure consistency. 


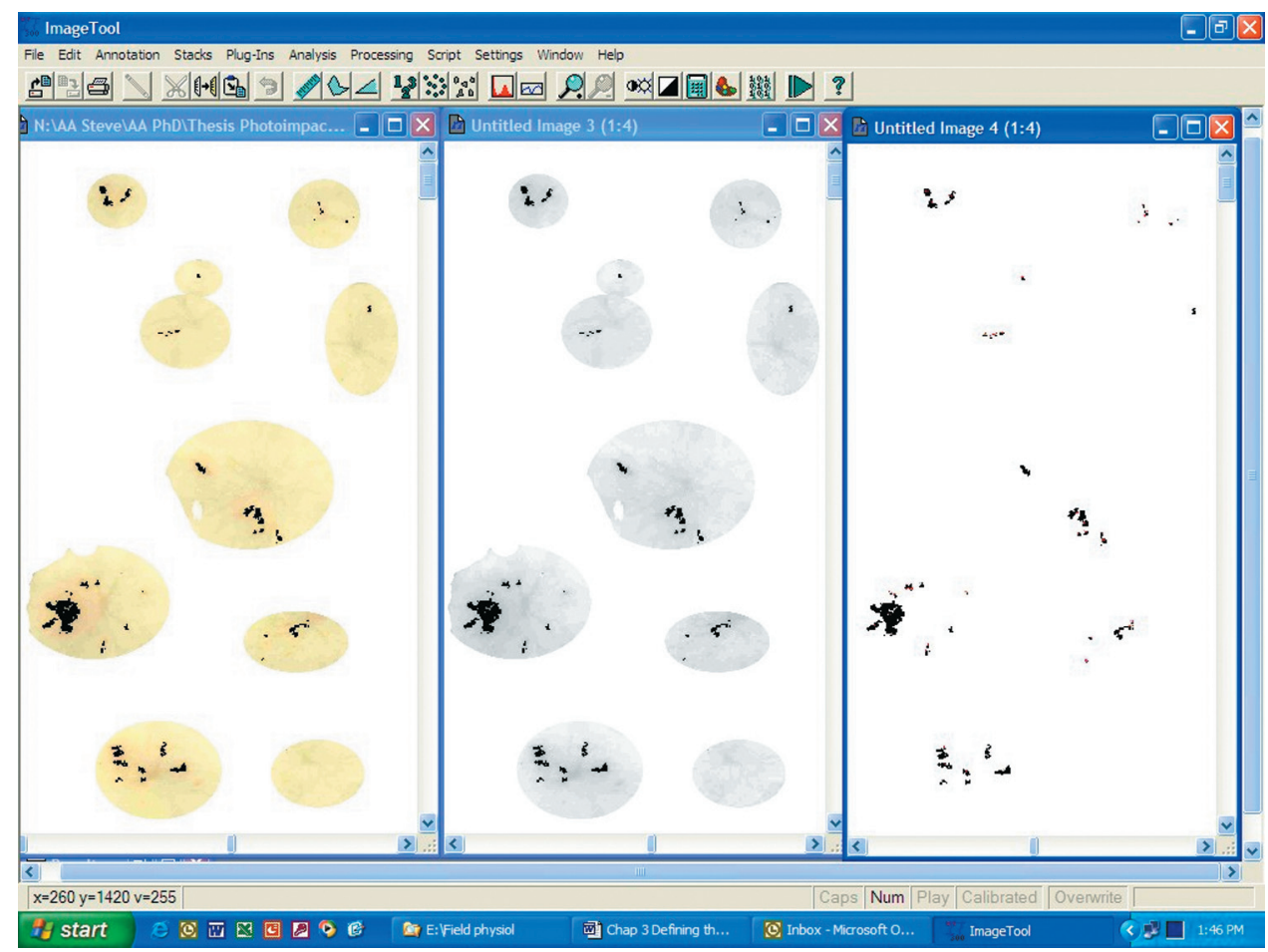

Figure 2. The UTHSCSA Image Tool for Windows (C) Ver. 3.00 display showing the initial imported digital image of potato tuber sections (with background colour removed) (left), the greyscale image of the sections (middle) and the analysed image with numbered BF lesions (right).

The enhanced images were saved as JPEG files and these were used to quantify the incidence of BF.

The enhanced images were imported or opened using the UTHSCSA Image Tool for Windows (c) Ver. 3.00 program developed at the University of Texas Health Science Centre, San Antonio, Texas, USA (Wilcox et al., 2002) (Figure 2, left). This program is available free of charge from the Internet at http://ddsdx.uthscsa.edu/dig/itdesc.html and its use is gratefully acknowledged. The program was used to calculate the actual area of BF-affected tissue in each tuber section. Once opened, the image was converted to greyscale in the 'Processing' menu, 'Color to Greyscale' automatic command (Figure 2, centre). The 'Analysis' menu was then opened and the commands 'Object Analysis' followed by 'Find Objects' entered. This latter command performs a count of lesions and numerically tags the BF lesions (Figure 2, right), presented on the threshold greyscale image (Figure 2, middle). Lesions were tagged using a font of suitable contrast colour (generally red or magenta). A more detailed tagged image is presented in Figure 3. Finally, the 'Analysis' menu was opened and the 'Object Analysis' and 'Analyze' command entered. This latter command counts the number of pixels in each lesion.

The data output included the area, length and width of each identified BF lesion (Figure 3). These data were copied from the ImageTool@ 3.0 data workbook 


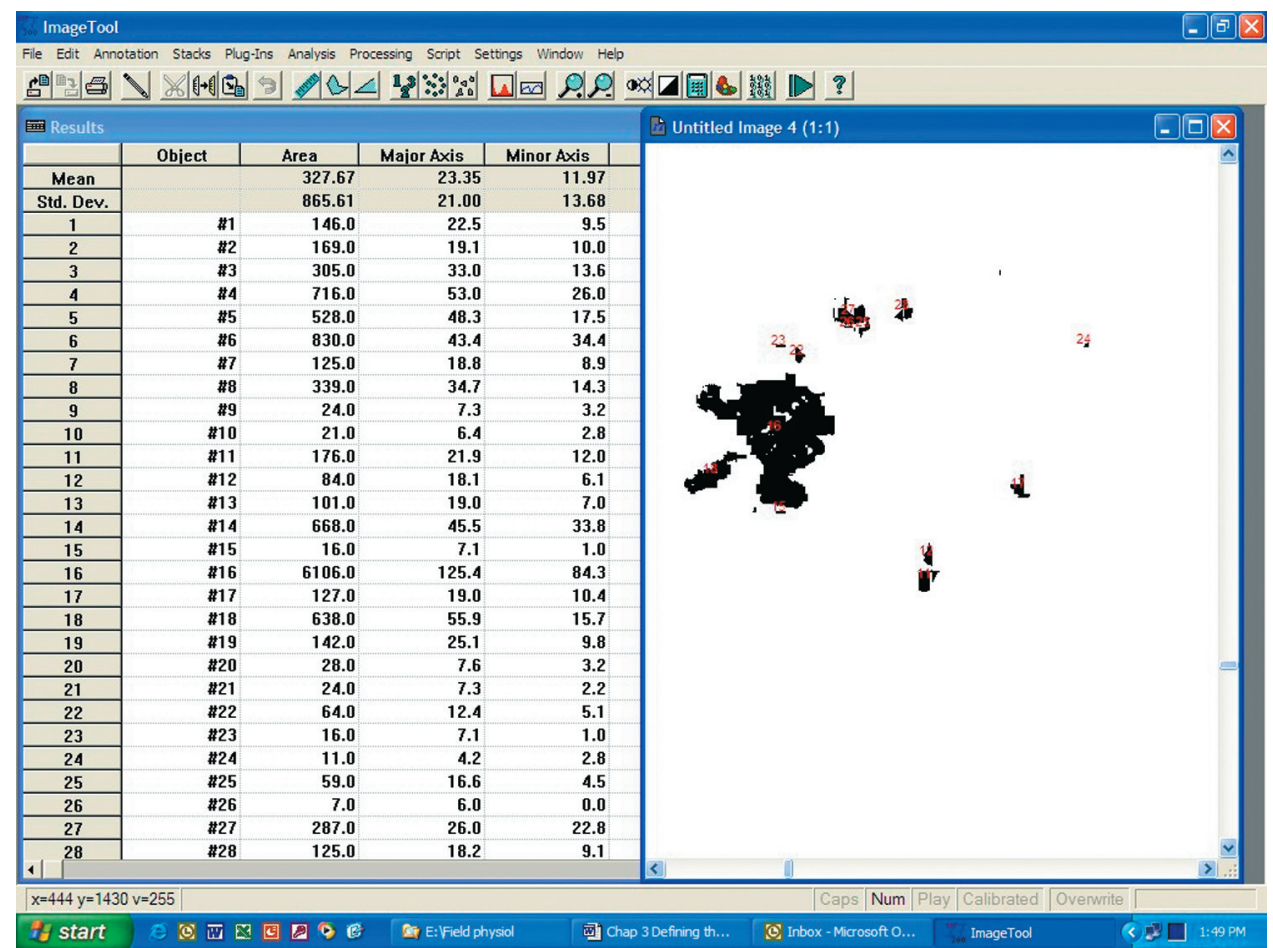

Figure 3. The UTHSCSA Image Tool for Windows (C) Ver. 3.00 display showing the tabulated output results page (left) and a magnified view of a selection of the labelled brown fleck lesions (right).

to a Microsoft ${ }^{\circledR}$ Excel 2000 9.0.3821 spreadsheet where area calculations $\left(\mathrm{mm}^{2}\right)$ were made. This was done by creating a $10 \mathrm{~cm}$ long line image (using Ulead ${ }^{\circledR}$ PhotoImpact ${ }^{\circledR} 7.0$ software) which was then processed through Image Tool@ 3.0, and the number of pixels calculated over the length of the line. A count of 7.9 pixels per lineal $\mathrm{mm}$ was determined; therefore, the area of each lesion was converted to $\mathrm{mm}^{2}$ by dividing the number of pixels by 62.41 .

The effectiveness of the digital enhancement technique in quantifying the incidence of $\mathrm{BF}$ was demonstrated by statistically comparing the digital data with visual-rating data derived from experimental data sets.

The first data set was obtained from a glasshouse pot experiment that evaluated the effects of four temperature treatments on the incidence of $\mathrm{BF}$ in potato cv. Sebago. The treatments included day and night temperature regimes of $18 / 13^{\circ} \mathrm{C}, 23 / 18{ }^{\circ} \mathrm{C}$, $28 / 23^{\circ} \mathrm{C}$ and $23 / 18^{\circ} \mathrm{C}$ imposed for $14 \mathrm{~d}$ from 98 days after planting (DAP). The tuber sections were prepared and digitally enhanced as described above. A visual rating from 0-4 was applied to each of the scanned sections, with 0 representing no $\mathrm{BF}$ incidence and 4 representing intense $\mathrm{BF}$ incidence of greater than an estimated $50 \%$ area covered. Both the digitally derived areas and visual ratings were summed for each tuber in each pot (replicate) and expressed as the total area affected with BF $\left(\mathrm{mm}^{2}\right.$ plant $\left.^{-1}\right)$ for the digital data and total rating per plant for the visual-rating data. 
Table 1. A comparison of significance levels for the effects of four treatments on BF incidence using digital data for total area affected with $\mathrm{BF}\left(\mathrm{mm}^{2}\right.$ plant $\left.^{-1}\right)$ and visual-rating data (total rating plant $\left.{ }^{-1}\right)$ in potato cv. Sebago tubers grown under glasshouse conditions.

\begin{tabular}{|c|c|c|c|c|c|}
\hline & \multirow[b]{2}{*}{ s.e. $d^{\dagger}$} & \multicolumn{4}{|c|}{ Day/night temperature regime $\left({ }^{\circ} \mathrm{C}\right)$} \\
\hline & & $18 / 13$ & $23 / 18$ & $28 / 13$ & $28 / 23$ \\
\hline \multicolumn{6}{|l|}{ Digital data } \\
\hline Untransformed & 347.7 & 27 & 736 & 211 & 881 \\
\hline Square root transformed & 6.22 & 3.3 & 21.0 & 9.6 & 23.5 \\
\hline $\log _{10}(x+1)$ transformed & 0.379 & 0.73 & 2.14 & 1.36 & 2.15 \\
\hline \multicolumn{6}{|l|}{ Visual-rating data } \\
\hline Untransformed & 2.29 & 0.60 & 4.70 & 2.46 & 4.46 \\
\hline Square root transformed & 0.599 & 0.57 & 1.59 & 1.09 & 1.69 \\
\hline $\log _{10}(x+1)$ transformed & 0.199 & 0.17 & 0.49 & 0.36 & 0.57 \\
\hline
\end{tabular}

${ }^{\dagger}$ Standard error of the difference for comparison of the mean values within each parameter, d.f. $=20$.

The experimental design was a randomized complete block with five replicates and the data analysed as a 1-way Analysis of Variance (ANOVA) using Genstat 8.1. Treatment effects were delineated using Fisher's least significant difference test. Square root and logarithmic $\left(\log _{10}(x+1)\right)$ data transformations were performed on both the digital and rating data to further delineate treatment effects. The standard error of difference between the means (s.e.d.) was also calculated.

For the second data set the incidence and development of BF over time was monitored in a field plot of potato cv. Sebago, planted on 7 July 2003 at Gatton, Queensland, Australia $\left(27^{\circ} 32^{\prime} \mathrm{S} ; 152^{\circ} 22^{\prime} \mathrm{E}\right)$. The plot consisting of five rows of $100 \mathrm{~m}$ length was divided length-wise into ten $10 \mathrm{~m}$ long subplots. Monitoring of BF commenced at 77 DAP. One plant from each of the 10 subplots was randomly harvested and tuber fresh mass and BF incidence were determined. This sampling procedure was conducted twice weekly until 112 DAP. The total area of tubers affected with BF $\left(\mathrm{mm}^{2}\right.$ plant $\left.^{-1}\right)$ was determined. Furthermore, the data for individual BF lesions were sorted by size to determine small lesions that were less than $5 \mathrm{~mm}^{2}$ in area. The aim of this procedure was to determine the number and area of newly initiated lesions (within about $0-3 \mathrm{~d}$ ), since the average size of a visible new lesion is in the order of $2-3 \mathrm{~mm}^{2}$. The measurements for each of the variables were expressed as the mean and s.e.d. of 10 plants sampled at each sampling date. Non-linear functions were fitted to the data and regression analysis conducted using SigmaPlot 8.0.

\section{RESULTS}

The ANOVA on the untransformed digital data from the glasshouse experiment showed an $F$ test probability of $P=0.087$ (Table 1), which was close to but not significant at the $5 \%$ level. In contrast, the $F$ test probability for the rating data of $P=$ 0.361 was far from significant. The use of the square root transformation and $\log$ transformation greatly improved the $F$ test significance levels for the digital data $(P=0.021$ and 0.007 , respectively) (Table 1$)$, but resulted in only marginal 
Table 2. A range of BF indices used in the evaluation of the effects of four temperature treatments on BF incidence using digital data in glasshouse-grown potato cv. Sebago tubers.

\begin{tabular}{|c|c|c|c|c|c|}
\hline \multirow[b]{2}{*}{ Index of BF incidence } & \multirow[b]{2}{*}{ s.e.d } & \multicolumn{4}{|c|}{ Day/night temperature regime $\left({ }^{\circ} \mathrm{C}\right)$} \\
\hline & & $18 / 13$ & $23 / 18$ & $28 / 13$ & $28 / 23$ \\
\hline Total area affected with $\mathrm{BF}\left(\mathrm{mm}^{2} \text { plant }^{-1}\right)^{\ddagger}$ & 0.379 & 0.73 & 2.14 & 1.36 & 2.15 \\
\hline Mean tuber area affected with $\mathrm{BF}\left(\mathrm{mm}^{2} \text { tuber }^{-1}\right)^{\S}$ & 2.69 & 1.5 & 10.6 & 4.6 & 12.0 \\
\hline Total number of BF lesions (plant ${ }^{-1}$ ) & 12.92 & 2.6 & 18.8 & 7.1 & 33.1 \\
\hline Number of BF lesions (tuber ${ }^{-1}$ ) & 4.66 & 0.6 & 5.1 & 1.6 & 9.8 \\
\hline $\mathrm{BF}$ lesion size $\left(\mathrm{mm}^{2}\right)$ & 2.158 & 1.2 & 8.2 & 3.4 & 7.3 \\
\hline
\end{tabular}

${ }^{\dagger}$ Standard error of the difference for comparison of the mean values within each parameter, $d . f .=20$.

${ }^{\ddagger} \log _{10}(x+1)$ transformed data.

$\S$ Square root transformed data.

improvement in the significance levels for the visual rating data $(P=0.265$ and 0.247 , respectively).

The use of digital imaging data allowed for the calculation and expression of a range of indices for BF incidence (Table 2). The total area affected with $\mathrm{BF}\left(\mathrm{mm}^{2}\right.$ plant $^{-1}$ ) was calculated as the sum of BF-affected area of each tuber of the plant. The mean calculated area of BF per tuber was also derived $\left(\mathrm{mm}^{2}\right.$ tuber $\left.{ }^{-1}\right)$. The total number of lesions per plant was summed for each tuber section and expressed as the total number of $\mathrm{BF}$ lesions per plant. The mean number of BF lesions per tuber was calculated (number tuber ${ }^{-1}$ ). From the data on BF area and lesion counts the mean BF lesion size $\left(\mathrm{mm}^{2}\right)$ could be calculated. Furthermore, the proportional area of each tuber affected with $\mathrm{BF}$ could be calculated by dividing the area affected with BF by the tuber cross sectional area and expressed as a percentage (data not shown).

Of particular value in the field experiment was the ability to identify the incidence of newly formed (small) lesions. These, when plotted over time (Figure 4a), gave results with much lower variability than the data for total area affected with BF (Figure 4b). The small lesion data also showed an earlier, largely linear, increase in area with time compared with the substantial increase in total BF area late in the season. Highlighting the flexibility of digital imaging and its capacity to draw relationships with other potato growth parameters was the relationship between tuber fresh yield and small lesion $\mathrm{BF}$ area (Figure 4c) and total area affected with $\mathrm{BF}$ (Figure 4d). As with the data for BF development over time, there was a clear, linear increase in small lesion BF area even with small tubers. In contrast, the fitted relationship between total area affected with $\mathrm{BF}$ and tuber fresh weight showed that BF increased exponentially with increasing tuber fresh weight (Figure 4d).

\section{DISGUSSION}

The digital data from the glasshouse experiment gave improved discrimination of treatment effects compared with the visual-rating data. The $F$ test probability for the untransformed digitally derived data was 0.087 and though not significant at 
a)

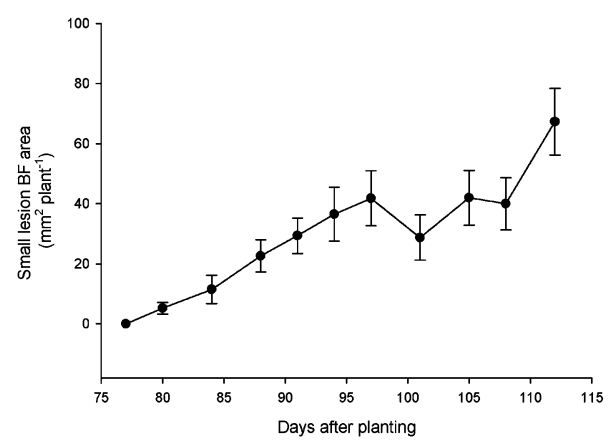

c)

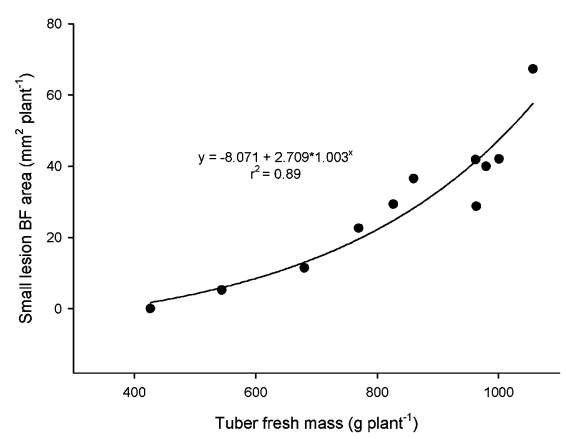

b)

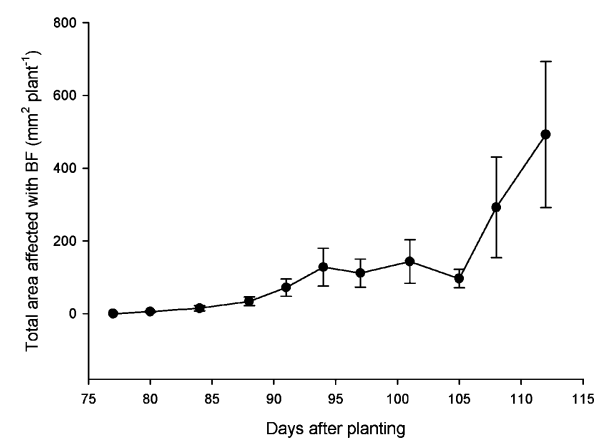

d)

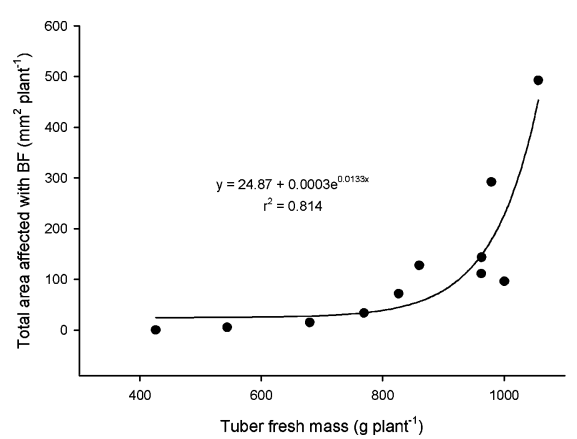

Figure 4. Change in a) small lesion $\mathrm{BF}$ area $\left(\mathrm{mm}^{2}\right.$ plant $\left.^{-1}\right)$ and b) total area affected with $\mathrm{BF}\left(\mathrm{mm}^{2}\right.$ plant $\left.{ }^{-1}\right)$ over time (bars are standard errors) and relationships between tuber fresh mass ( $\mathrm{g}$ plant ${ }^{-1}$ ) and c) small lesion BF area $\left(\mathrm{mm}^{2}\right.$ plant $\left.^{-1}\right)($ s.e. $d=7.12)$ and $\left.\mathrm{d}\right)$ total area affected with $\mathrm{BF}\left(\mathrm{mm}^{2}\right.$ plant $\left.^{-1}\right)($ s.e.d. $=71.0)$ and over a period of 77-112 DAP in field-grown potato cv. Sebago in 2003.

$P \leq 0.05$ was nonetheless much better than that of the visual rating $(P=0.361)$ (Table 1). However, the variance of the data showed a skewed distribution which violates one of the underlying assumptions for ANOVA that variance is normally distributed. Both square root and log transformations were justifiable manipulations of data for analysis of $\mathrm{BF}$ incidence.

The BF lesions begin in isolated cells, and the subsequent lesion development and expansion in a tuber cross-section is in a roughly circular pattern (viz. the square of the radius); hence, a square root transformation is valid. Also, the initiation of BF lesions can occur as early as about 77 DAP whilst tuber harvest is some 30-40 days later, typically at about 112 days for cv. Sebago. The total area affected with BF increased over time particularly late in the season (Figure 4) and hence a log transformation is also valid. Square root and logarithmic transformations $\left(\log _{10}(x+1)\right)$ of the digital and visual-rating data were conducted, which resulted in normalized variance and greatly improved discrimination of treatment effects for the digital data only (Table 1). 
Though digital enhancement is more complex and time consuming than simply visually rating for $\mathrm{BF}$, the procedure allows both the identification and measurement of lesion number and the area of tuber section affected by BF. The digital data allowed for $\mathrm{BF}$ incidence to be expressed as a range of indices not previously used. This included the total area affected with BF per plant, mean tuber area affected with BF, the total number of $\mathrm{BF}$ lesions per plant, the mean number of $\mathrm{BF}$ lesions per tuber, the average $\mathrm{BF}$ lesion size and the proportional area of each tuber affected with BF. The technique provides a more objective and flexible means for quantifying the incidence of BF whilst lowering inherent variability allowing improved interpretation of experimental results compared with visual rating.

The digital data can also be refined to determine lesions of a specific size. Since BF lesions commence as single affected cells of about $0.04 \mathrm{~mm}^{2}$, the counts and area of lesions of this size or slightly bigger can be determined. This is particularly useful in relating factors that may specifically influence the initiation and development of BF. Using field experimental data in the present study, the response in the development of small lesion $\mathrm{BF}$ area over time and with tuber fresh mass was distinctly different from that of the total area affected with BF.

In contrast to the rating data, the digital data allow for linear and non-linear regression models to be fitted. In statistical analysis of variance, where the condition for normally distributed variance does not hold, the digital data can be transformed. Analysis of covariance is also easily conducted to include the effects of other variables (e.g. foliage mass, stem number). The collection of quantitative data as opposed to subjective-based data allows better statistical delineation of treatment effects on BF and hence greater opportunity to understand factors related to its incidence.

\section{CONCLUSION}

The digital imaging technique described in this study allows for the accurate quantification of the area affected by $\mathrm{BF}$ in potato tubers and the capacity to count the number of lesions. This permits a range of useful indices of BF incidence to be calculated. Importantly, the generation of digital data allows for the use of more advanced statistical analyses (e.g. data transformation, regression analysis and covariance), a reduction in experimental error, and provides the potential to better understand BF development and its underlying causes. Finally, the underlying principles may be used in other contexts, including the development of pathological diseases (Kowalski and Cassells, 1999; Niemera et al., 1999), plant and leaf area development and root growth.

REFERENCES

Ahmadi, A., Mobarak, H. and Osguthorpe, J. (1960). The effect of time of planting on occurrence of internal brown spot in the potato variety Arran Banner in Lebanon. American Potato fournal 37:23-27.

Brown, C. R., McNabnay, M. and Dean, B. (1999). Genetic characterization of reduced melanin formation in tuber tissue of Solanum hjertingii and hybrids with cultivated diploids. American Fournal of Potato Research 76:37-43.

Cassells, A. C., Kowalski, B., Fitzgerald, D. M. and Murphy, G. A. (1999). The use of image analysis to study developmental variation in micropropagated potato (Solanum tuberosum L.) plants. Potato Research 42:541-548. 
Collier, G. F., Wurr, D. C. E. and Huntington, V. C. (1980). The susceptibility of potato varieties to internal rust spot. fournal of Agricultural Science, Cambridge 94:407-410.

Hiller, L. K., Kohler, D. C. and Thornton, R. E. (1985). Physiological disorders of potato tubers. In Potato Physiology, 389-455 (Ed. P. H. Li). Orlando, Florida: Academic Press.

Kowalski, B. and Cassells, A. C. (1999). Mutation breeding for yield and Phytophthora infestans (Mont.) de Bary foliar resistance in potato (Solanum tuberosum L. cv. Golden Wonder) using computerized image analysis in selection. Potato Research 42:121-130.

Niemera, B. A., Kirk, W. W. and Stein, J. M. (1999). Screening for late blight susceptibility in potato tubers by digital analysis of cut tuber surfaces. Plant Diseases 83:469-473.

Novak, V., Mann, G. and Schrodter, G. (1986). Effects of age at harvest and irrigation near maturity on the incidence of internal brown fleck in potato tubers. Australian fournal of Experimental Agriculture 26:129-132.

Olsen, N. L., Hiller, L. K. and Mikitzel, L. J. (1996). The dependence of internal brown spot development upon calcium fertility in potato tubers. Potato Research 39:165-178.

Sterrett, S. B. and Henninger, M. R. (1991). Influence of calcium on internal heat necrosis of Atlantic potato. American Potato fournal 68:467-477.

Stevenson, W. R., Loria, R., Franc, G. D. and Weingartner, D. P. (2001). Compendium of Potato Diseases. Minnesota: The American Phytopathological Society.

Strand, L. L., Rude, P. A. and Clark, J. K. (1986). Integrated Pest Management for Potatoes in the Western United States. Oakland, California: University of California.

Wilcox, D., Dove, B., McDavid, D. and Greer, D. (2002). UTHSCSA Image Tool for Windows (C) Ver. 3.00. (University of Texas Health Science Centre, San Antonio, Texas, USA). 